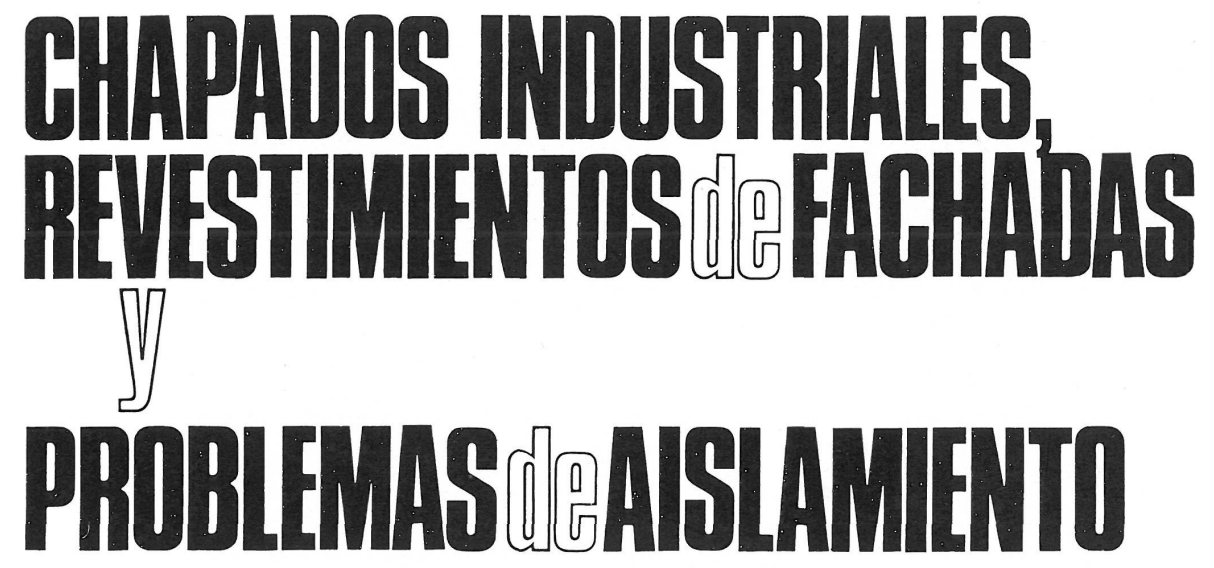

GEORGES RODRIGUEZ

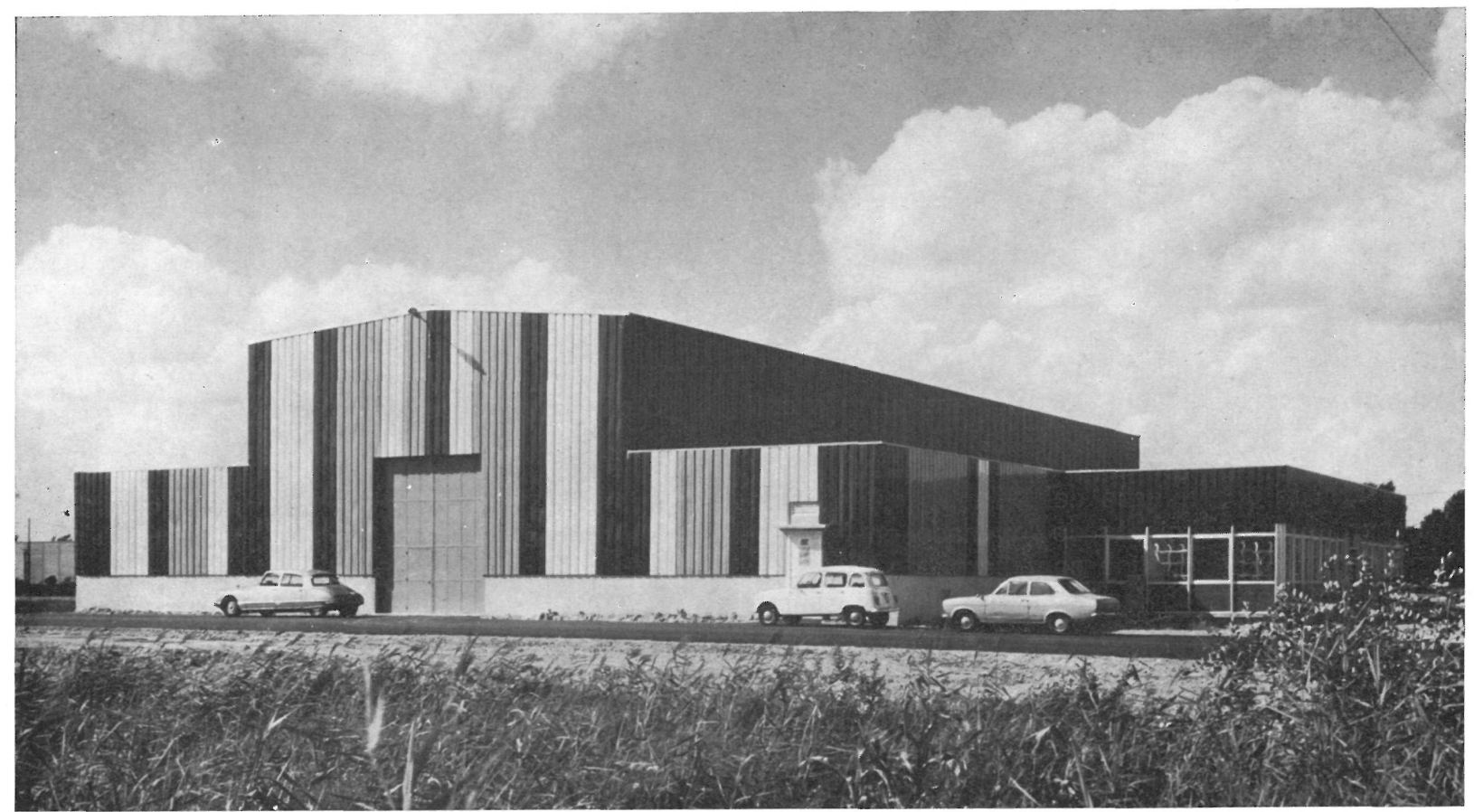

S i n O p is En construcción, cada día aparecen nuevas técnicas para resolver, de una manera más efectiva, los problemas de siempre o los que puedan surgir en las obras actuales.

Los problemas de aislamiento son difícilmente solucionables en los inmuebles de viviendas si no se utilizan la vida del edificio. Para este fin se pueden utilizar los palastros nervados prelacados, los chapados de aluminio en hojas y las hojas de cobre y plomo, si bien estos dos últimos, por su elevado precio, quedan reservades para contados edificios de caracter monumental. En las construcciones corrientes se utilizan placas de amianto-cemento, en diversidad de formas y calidades, sirviendo igualmente para el aislamiento de muros

Los problemas de aislamiento son dif́ícilmente solucionables en los inmuebles de viviendas sì no se utilizan los materiales y sistemas adecuados. La colocación de un buen aislante protege de la humedad y ahorrá ticos, hasta los más modernos obłenidos por mezcla de fibra de celulosa, amianto y vermiculita. En último

$882-2$ el resultado más idóneo.

El chapado es, de hecho, un muro-cortina especialmente adaptado a la construcción industrial

Las chapas de acero galvanizado y de aluminio, cuyas aplicaciones son todavía numerosas, sufren la competencia de las chapas pretratadas en fábrica, las cuales resisten mejor la corrosión, y tienen un mejor aspecto una vez colocadas en obra por el proceso de coloración que han sufrido. 


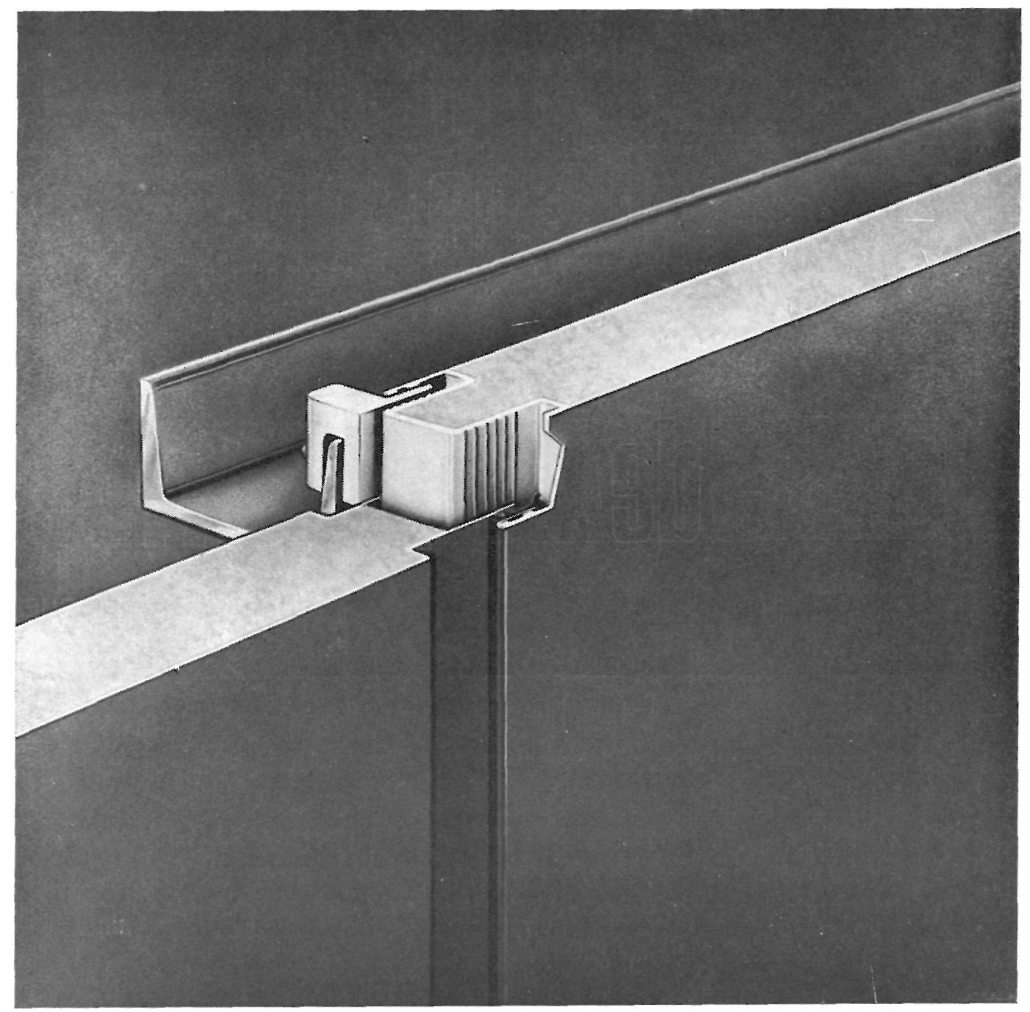

Comenzaremos el estudio por el material más antiguo. ¿Cómo se produce la chapa o palastro de acero galvanizado?

El palastro de acero, base del palastro galvanizado, se obtiene de dos maneras: en forma de hoja, por el procedimiento de laminado en hojas, en trenes mecanizados de laminación; y en forma de banda, de varios centenares de metros y enrollada en bobinas, obtenida en grandes y modernos trenes de laminación de largas bandas.

La galvanización consiste en sumergir en un baño de zinc en fusión un palastro de acero, previamente sometido a diversos tratamientos superficiales, destinados a dejarlo completamente limpio y a darle las características mecánicas requeridas.

De igual forma que la chapa de acero se presenta en hojas o en bandas enrolladas en bobinas, el galvanizado puede hacerse "hoja a hoja" o "en continuo".

En el primer procedimiento los palastros son arrastrados, unos detrás de otros, hacia el baño de zinc en fusión, después de haber sufrido los tratamientos superficiales requeridos (desoxidación, enjuagado, etc.); a la salida del baño, los palastros son secados, enfriados y cepillados.

En el segundo procedimiento, de galvanización "en continuo", las bobinas se sueldan eléctricamente por sus extremos, unas a otras, de forma que no haya ninguna interrupción en el proceso de galvanizado; la banda penetra en dos hornos sucesivos donde se operan los tratamientos de superficie necesarios (recocido, desoxidación, etc.). Sin entrar en contacto con el aire, la banda pasa entonces al baño de zinc en fusión, regulándose el tiempo de paso en función de la cantidad de material a depositar sobre la banda. A la salida del baño el palastro se enfría en un largo pasillo ventilado, siendo posteriormente cepillado, enrollado, etc.

En el transcurso de esta operación se efectúan regularmente numerosos controles, en especial de la adherencia del zinc y del peso del mismo que reviste el palastro.

La chapa de acero galvanizado, así obtenida, puede tener un espesor variable de 0,20 a 5,00 mm, y una anchura que oscila entre 0,50 y $1,50 \mathrm{~m}$, siendo la más habitual la de 1,00 m. 
La longitud máxima es, corrientemente, de 8 a $10 \mathrm{~m}$ para el palastro galvanizado en hojas, y de $1.500 \mathrm{~m}$ para el palastro galvanizado en bandas.

Debido a la excelente capacidad del acero para sufrir deformaciones, y gracias a la notable adherencia del zinc que reviste sus dos caras, el palastro de acero galvanizado puede, fácilmente, ser: ondulado, nervado, perfilado, grapado, plegado, curvado y embutido. Además puede pintarse y soldarse.

La utilización tradicional del palastro de acero galvanizado para la cobertura y el chapado no ha dejado de desarrollarse; y así, los palastros planos, ondulados, elementos de grandes longitudes, revestimientos autoportantes y accesorios de cubierta, son bien conocidos y cada vez más empleados en la construcción de casas unifamiliares, inmuebles de viviendas o de ofici. nas, fábricas, edificios agrícolas, etc.

El palastro de acero galvanizado en su forma plana juega, por otra parte, un papel cada vez más importante en los campos de muros-cortina y paneles de fachada, suelos, cielorrasos, techos acústicos y tabiques, así como en la fabricación de carpinterías metálicas, ventanas, postigos de ventanas, parasoles, cortinas o persianas móviles, puertas, puertas corta-fuegos, cierres de garaje, puertas correderas y basculantes, elementos de calefacción, ventilación, acondicionamiento de aire, depuración y elementos para el paso de canalizaciones.

En el caso de que interesen las aplicaciones de este material en la construcción, es esencial conocer la velocidad de corrosión. Refirámonos, por ejemplo, al caso de un clima rural húmedo. La velocidad de corrosión atmosférica del zinc depositado por galvanización al calor es del orden de 0,7 a 2,2 micras por año. Con el espesor corriente de un revestimiento galvanizado, que oscila entre 56 y 112 micras, es frecuente encontrar, en las zonas rurales, palastros u otros objetos galvanizados que han resistido a la herrumbre durante más de 50 años.

Esta duración se reducirá, naturalmente, si el ambiente es corrosivo, siendo entonces aconsejable la utilización de pinturas ricas en zinc, que se presentan bajo la forma de metal líquido constituido por un $95 \%$ de zinc y un $5 \%$ de trabazón. Se trata, en cierta manera, de zinc en solución. Con estas pinturas se prolonga y completa la protección obtenida por galvanización o metalización. La pintura reacondiciona, por su excelente agarre sobre la superficie tratada. las zonas que parecían haber sido deterioradas.

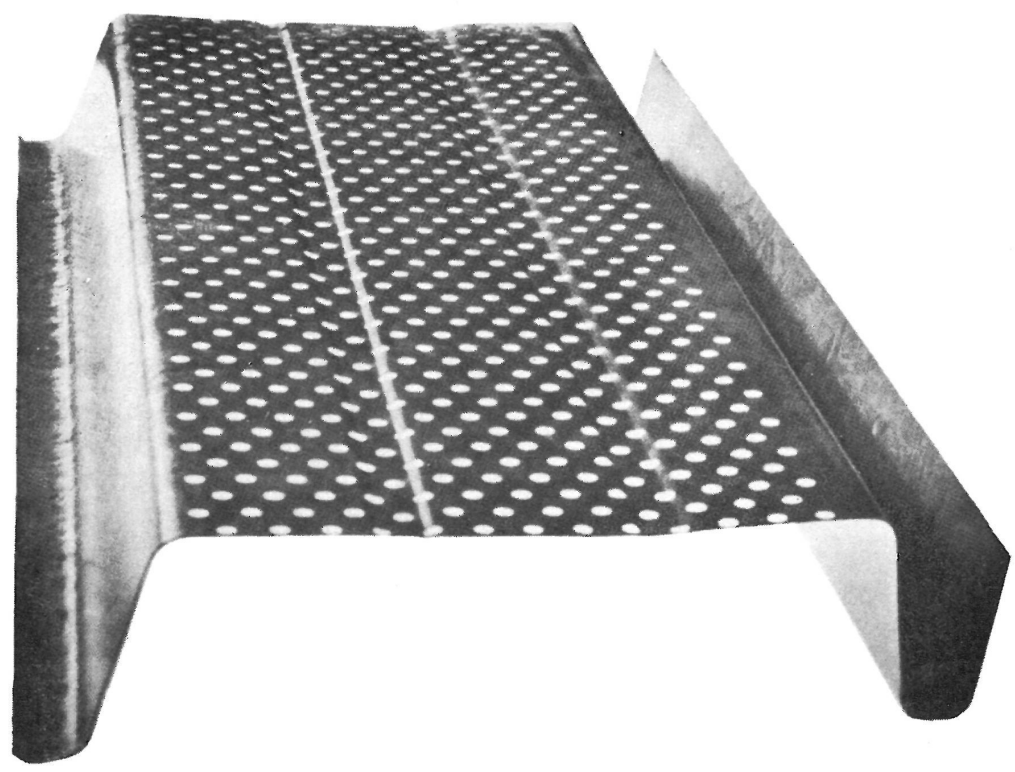


Un buen ejemplo de utilización a gran escala, en condiciones difíciles de solucionar, es el chapado y revestimiento de edificios del Complejo Siderúrgico de Dunkerque, realizados en palastro de acero galvanizado.

La evolución progresiva del chapado, ya se trate de palastros ondulados galvanizados, de hojas metálicas o de palastros de acero revestidos con un lacado, ha permitido superar el principal obstáculo: el defecto de aislamiento de los edificios.

Esta cuestión ha tomado, desde la crisis de energía, una significación especial debido a que la calefacción de los locales resulta cada vez más onerosa.

El chapado simple, con palastro único y los nervios más o menos acentuados, aplicado sobre una estructura, se limita a proteger del viento, del hielo, de la lluvia o de la nieve, el interior del edificio.

Para mejorar las condiciones ambientales en estos locales, a los palastros nervados se les ha añadido un aislante, $y$, naturalmente, se ha llegado a la obtención de "paneles de fachada" que llevan un aislante cogido entre dos palastros nervados.

Este material aislante puede ser una espuma de plástico rígida que asegura la unión entre los dos paramentos, o bien un aislante mineral semirrígido incluido entre las dos paredes metálicas.

La utilización de tales paneles es posible a la vez como elemento de tabiquería, de chapado o de cobertura, con los mismos elementos de fijación.

\section{PALASTROS NERVADOS PRELACADOS}

Teniendo en cuenta lo expuesto anteriormente, los palastros de acero nervados, revestidos en fábrica de una laca cocida al horno y coloreados con el mismo tinte de la laca, son los preferidos de constructores y arquitectos. La estética del chapado juega un papel esencial en el aspecto definitivo, y sí se puede decir que es "decorativo" un edificio industrial de cierta envergadura.

El prelacado, o lacado en fábrica antes de la comercialización, se realiza con resinas sintéticas coloreadas: resinas epoxi, de poliéster, vinílicas, acrílicas, alkídicas, etc., mediante la aplicación de una primera capa de reducido espesor, por ejemplo del orden de 5 a 7 micras de resina epoxi, seguido de una capa de acabado de 20 micras.

La superposición de capas protectoras sobre una misma superficie, puede dar un espesor más fuerte según la resina puesta en obra. Tanto es así que los "plastisols" y "organosols" vinílicos son susceptibles de llegar a 100 micras de espesor sobre la superficie metálica tratada. Las películas Ilamadas "colas", aplicadas sobre palastros, son aún más espesas. Los polímeros clorados dan una película protectora de 200 a 300 micras; los acrílicos, de 80 micras, y de 40 a 50 micras los polímeros fluorados. Una poliamida como la "Rilsan", de una marcada resistencia a las agresiones químicas, dará una película de 150 a 200 micras de espesor.

La elección entre semejante gama de posibilidades está dictada por la corrosividad del medio en el cual los chapados o las coberturas se encuentren situados.

Hay todavía otros ingredientes que sirven como revestimiento de palastros prelacados, como son las siliconas y las glycerophtalicas o, eventualmente, mezclas compatibles.

En cuanto a la aplicación de la "Rilsan", se procede a un empolvado electrostático y a una fusión que da lugar a una capa espesa y uniforme que reviste por igual el corte de los palastros. Cuando se trata de paneles de fachada, se admite, normalmente, dejar la cara situada al inte- 

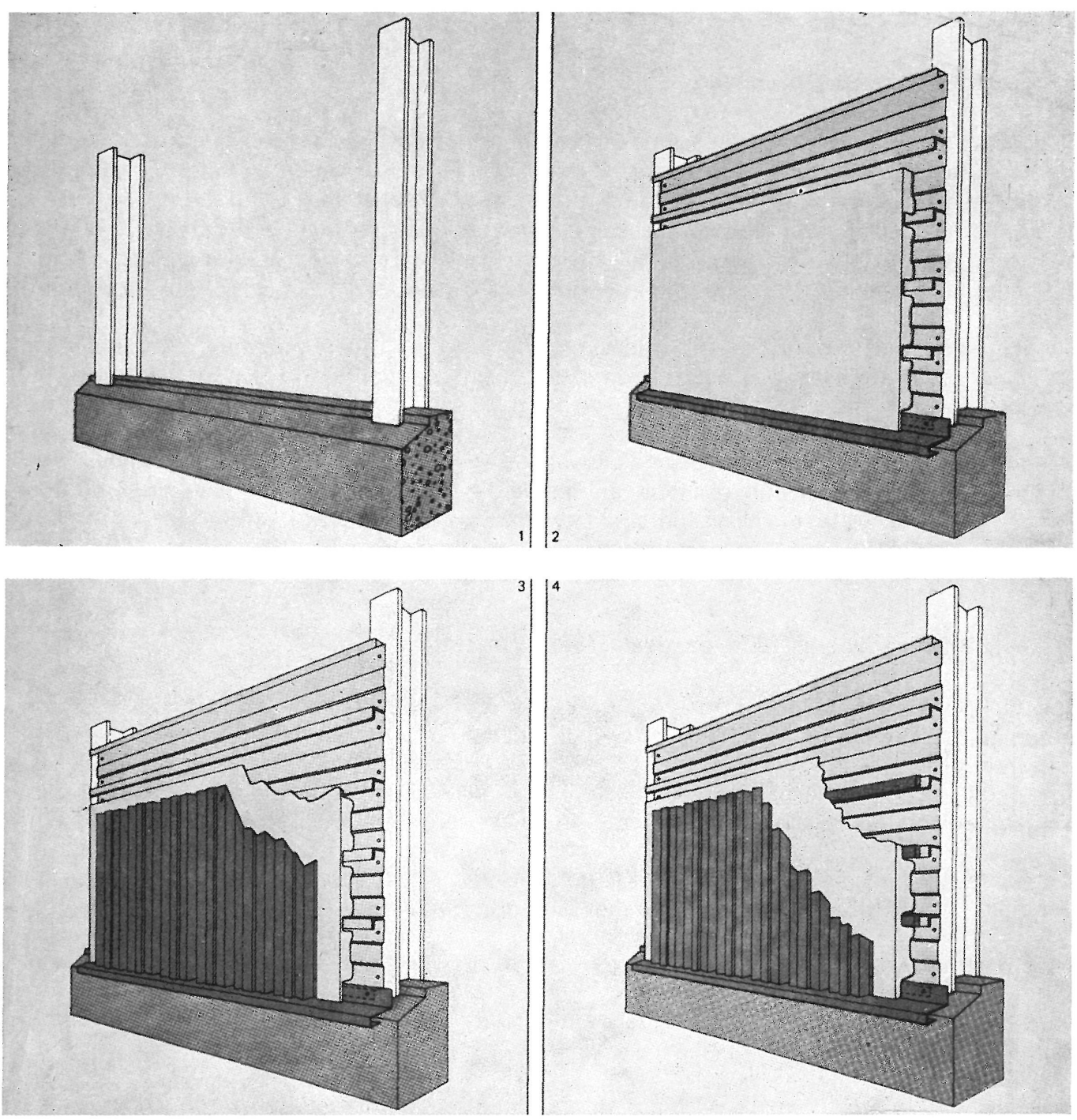

CONSTITUCION Y MONTAJE DE UNA FACHADA TIPO ACIEROID

Sobre la estructura, una vez montada, pintada y ajustada, descan sando sobre el zócalo (1), la fachada Acieroid se compone de tres elementos: perfiles interiores, en su parte plana, colocados horizontalmente y fijados sobre los pilares (2); manta de lana
de vidrio, situada encima del conjunto de la superficie (2); tiras de contacto, que aseguran la estanquidad y acabado de la fachada; perfil exterior, que se remacha entonces sobre los bordes de los perfiles interiores a través del aislamiento (3). En casos particulares se refuerza el aislamiento térmico aumentando la manta aislante y añadiendo tiras especiales entre las

rior sin revestimiento, cualquiera que sea su naturaleza. Con esto se consigue una apreciable economía, pues la cara interior raramente queda expuesta a la corrosión.

Afortunadamente los precios respectivos de los chapados prelacados constituyen el elemento determinante para su elección, aunque esta consideración no debe ser la única.

La opacidad de estos chapados hace necesario intercalar placas translúcidas para mejorar la iluminación interior de los locales.

Las ensambladuras y fijaciones están ya muy estudiadas, por lo que no producen dificultades para su puesta en obra.

Cuando el chapado de doble pared es montado a pie de obra, por ejemplo para construir un muro-cortina industrial, es preciso ir colocando sucesivamente todos sus componentes. 


\section{CHAPADOS EN HOJAS DE ALUMINIO}

\section{Coberturas en cobre y en plomo}

El cobre y el plomo en hojas están reservados, en principio, para los mejores inmuebles y para los monumentos considerados como eternos. Sus precios hacen prohibitiva su utilización en la construcción corriente. En la basílica de Lourdes existe una cúpula enteramente revestida de plomo. Otros monumentos célebres están revestidos con planchas de cobre, que toman una bellísima coloración con la pátina del tiempo. Por el contrario, el aluminio es de utilización corriente, colocándose las planchas al desnudo o revestidas con un baño protector.

Su ligereza y sus propiedades térmicas son apreciables. Su resistencia a los humos industriales y su poder reflectante permiten emplearlas en condiciones próximas a las del zinc (palastros ondulados y tejas).

Desde hace tiempo se utilizan paneles vaciados de aleación aluminio-silicio, que se fijan directamente a la armadura con ganchos de fundición, y que están formados por una doble pared de palastros de aluminio, con un aislante térmico incorporado entre ellos. Una idea semejante fue lanzada hace ya más de 40 años.

\section{Placas translúcidas y amianto-cemento (fibro-cemento)}

Los plásticos translúcidos $u$ opacos, presentados en placas, pueden constituir el cerramiento propiamente dicho, si son opacos, o dejar pasar la luz si son translúcidos.

Las ondulaciones o nervaciones de los mismos han sido estudiadas de forma que permitan los empalmes con las placas del chapado metálico del amianto-cemento.

Las placas translúcidas pueden ser, a elección del constructor, incoloras o teñidas, presentándose en este último caso, más frecuentemente, en los colores amarillo, verde o azul.

Esta particularidad incita a volver a pensar en el vidrio armado de pared simple o doble.

El vidrio puede presentarse en forma de perfil, con sección en $U$, dando al revestimiento una rigidez suficiente.

También existe en el mercado un material resultante de la combinación de fibras de vidrio y de una carga mineral, cuya unión se asegura mediante una materia orgánica termoendurecida.

Para ciertos muros-cortina de inmuebles colectivos o destinados a oficinas, se pueden utilizar vidrios reflectantes.

Todas estas cualidades pueden ser utilizadas por los arquitectos para disimular los falsos techos o los huecos de instalaciones.

Los productos de fibrocemento (amianto-cemento) presentan una gran variedad en cuanto a la elección de las nervaduras $u$ ondulaciones. Su aspecto natural, de color gris claro, puede modificarse, por pigmentación, hasta llegar al oscuro. Citaremos, por ejemplo, el caso de la colegiata de Roncesvalles, cuya techumbre ha sido enteramente rehecha, en el transcurso del año 1975, con placas onduladas de fibrocemento teñido en pardo, lo que le da un aspecto mucho más estético que los palastros ondulados galvanizados que figuraban en este lugar anteriormente.

Ciertos elementos decorativos vaciados, impropiamente designados bajo el apelativo de "puntas de diamante", mejoran el aspecto exterior.

A pesar de todas estas posibilidades de aplicación, las placas de amianto-cemento se utilizan, prácticamente, para la realización de fachadas de doble pared o como contra-revestimiento aislante. Las placas translúcidas pueden alternarse con éstas para la mejor iluminación del interior. 
Las dimensiones de todas las placas, independientemente de su naturaleza, están normalizadas o estandarizadas para permitir su intercambiabilidad. Son las posibilidades de transporte las que limitan la fabricación de placas de mayor longitud, las cuales pueden alcanzar de 8 a $10 \mathrm{~m}$ para anchuras de 700 a $1.250 \mathrm{~mm}$.

El vidrio armado puede utilizarse hasta alturas de $5,10 \mathrm{~m}$ en el caso de doble pared, $\mathrm{y}$ hasta 4,00 $\mathrm{m}$ para la pared simple, gracias a que la sección en $U$ le confiere una gran rigidez.

El material constituido de fibras de vidrio y carga mineral, con añadido de un termoendurecedor, se puede colocar en obra hasta en largos de 8 a $10 \mathrm{~m}$, con una anchura útil de 0,90 m.

Respecto a los trabajos de colocación propiamente dichos, se puede decir que para los placados se llevan a cabo de manera diferente a como se realiza para un muro-cortina industrial, el cual precisa la sucesiva colocación de cada uno de sus componentes.

Esta colocación necesita, en obra, medios mecánicos simples. El desmontaje parcial o total quita posibilidades para efectuar modificaciones o reemplazar elementos.

Si se trata de paredes simples, los elementos se fijan sobre un armazón ligero, en general liso, horizontal, de madera o metálico, fijado sobre las vigas de la armadura. Las placas se colocan verticalmente, recibiéndose en el sentido opuesto al de los vientos de lluvia dominantes. La colocación comienza por la fila inferior, la cual se recubre, por solape, con los elementos de las filas superiores. La fijación se hace con la ayuda de tirafondos, tornillos autorroscados o pernos-gancho. Según los casos, no hay que olvidar la interposición de segmentos de estanquidad. Estas ataduras de fijación pueden ser disimuladas entre dos nervios principales, para que, estéticamente, no sean desagradables. Sin embargo, estas fijaciones, convenientemente repartidas, pueden contribuir al aspecto decorativo.

Las fachadas-cortina industriales se colocan de la misma forma.

La pared interior se dispone horizontalmente sobre la estructura del edificio, después que el aislamiento se ha colocado y fijado en su lugar. Seguidamente se procede a la colocación de la pared exterior.

\section{INMUEBLES RESIDENCIALES Y PROBLEMAS DE AISLAMIENTO}

El chapado ha sido concebido, desde siempre y sobre todo, pensando en las construcciones industriales o en inmuebles de grandes dimensiones. Pero se pueden extender sus aplicaciones a los edificios de menor importancia, e incluso a las viviendas unifamiliares.

Una aplicación reciente, llamada a desarrollarse, es la que resulta de las reglamentaciones que muchos países europeos han dictado respecto al aislamiento de los edificios, con el fin de economizar combustible en la calefacción. Se ataca así las reformas de construcciones antiguas, y se acuerdan ventajas fiscales que favorecen a los propietarios que consienten en hacerlas. Desde este momento se utiliza el chapado aplicado al aislamiento.

El material aislante puede colocarse directamente sobre la pared construida o, también, manteniendo una separación para favorecer la ventilación. El palastro se pone de manera convencional, ya sea sobre la fachada o bien sobre la estructura, sirviendo a la fijación del aislante. Esto asegura a la vez que, tanto el aislante como la fachada de la construcción, queden protegidas del agua, no exponiéndose a la intemperie. Este procedimiento puede utilizarse cuando el exterior del edificio se encuentra en mal estado.

En ciertas circunstancias la pizarra puede ser elegida como revestimiento multifuncional. Dicha aplicación es bien conocida desde antiguo, y se ha utilizado, revistiendo muros, en los países muy lluviosos. Su eficacia no puede ser negada, máxime cuando tiene un precio de coste de fabricación razonable. Además, nuestros antepasados no disponían de otras técnicas para proteger los muros de la humedad.

De manera general, el beneficio económico que supone la utilización de materiales aislantes no puede concretarse en un porcentaje definido, depende, en efecto, de la arquitectura, del tipo de construcción, del clima, y hasta del modo de vida de los ocupantes. 
Es cierto que $15 \mathrm{~cm}$ de material aislante dan lugar a una reducción sustancial del gasto de calor; sin embargo, la puesta en obra de tales materiales, en particular en la construcción antigua, puede resultar imposible o cara en relación con el resultado esperado.

En estos casos se presenta una solución, y es la del aislamiento exterior. Permite no modificar nada en el interior de la vivienda o edificio, consiguiéndose una eficacia igual o superior a la del aislante tradicional, debido a que suprime los puentes térmicos.

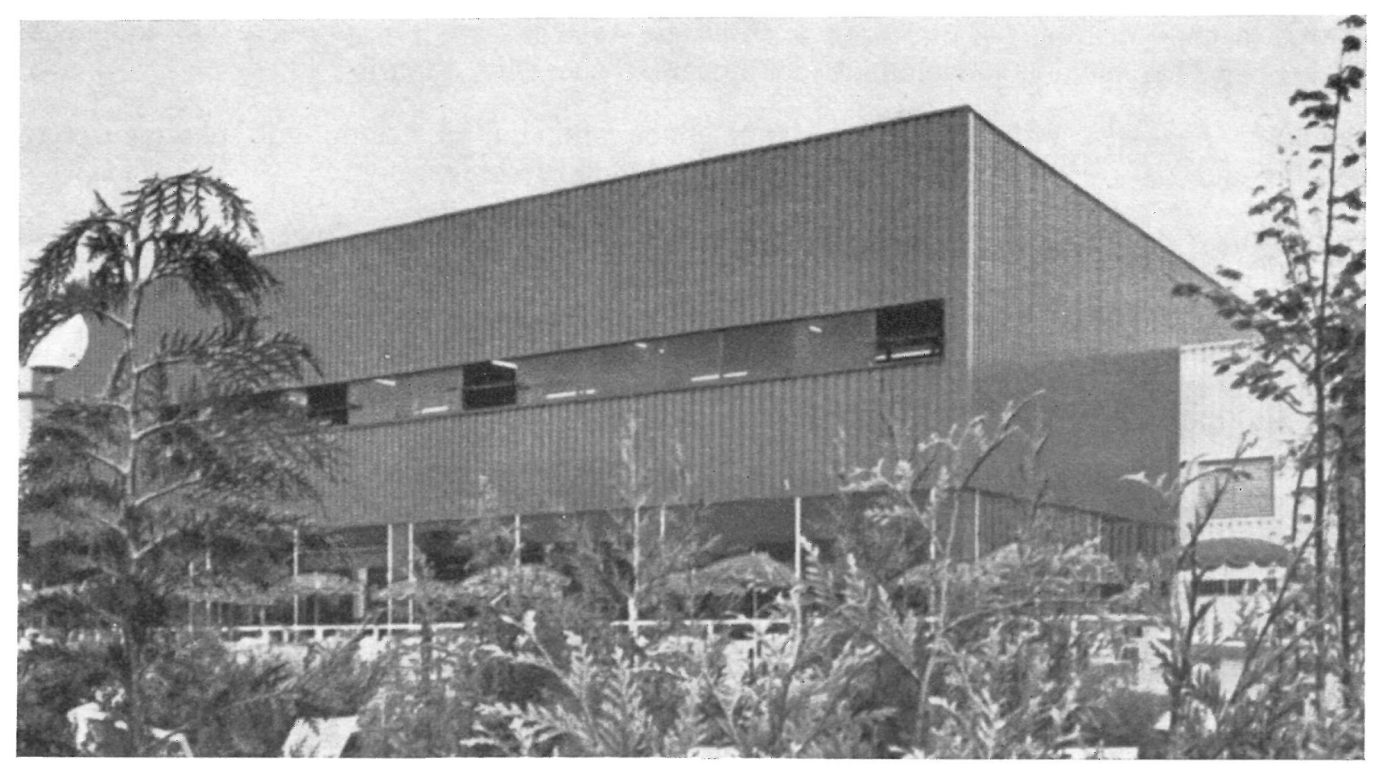

Aspecto exterior de un chapado tipo Smacacier.

Colocación de un suelo de acero perfilado Smacacier.
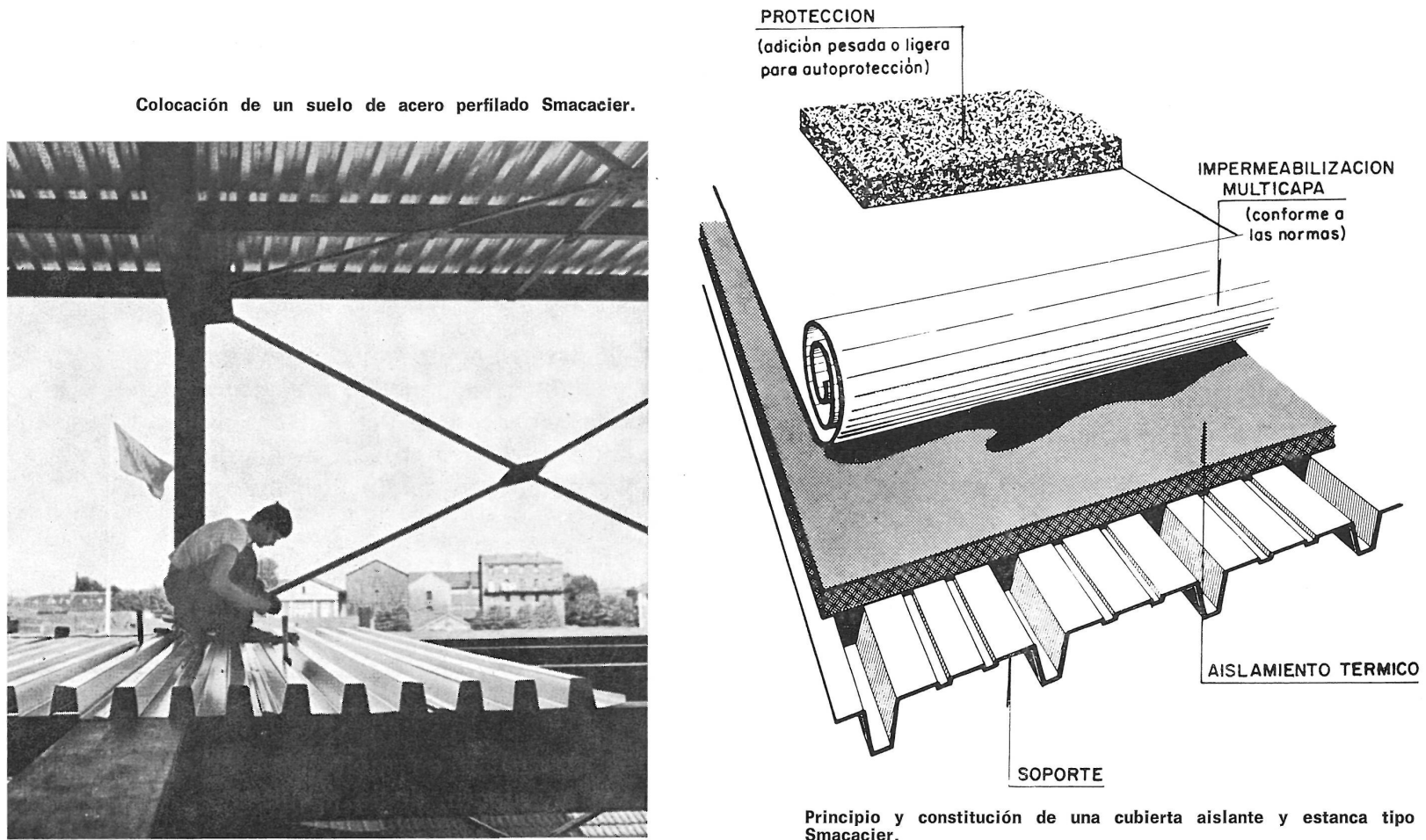

Principio y constitución de una cubierta aislante y estanca tipo Smacacier. 
Entre los materiales de aislamiento es de notar las mutaciones que favorecen sus aplicaciones hacia los objetivos que se exponen aquí.

El amianto, que se presentaba solamente en espuma y en cartón, reviste ahora el aspecto alveolar o en nido de abeja, con características mecánicas elevadas, hasta el extremo de que estos elementos pueden concebirse como sustentantes.

La arcilla expandida -obtenida en una hora a la temperatura de tratamiento de $1.400^{\circ} \mathrm{C}$-, la arcilla polimerizada a baja temperatura -a $150^{\circ} \mathrm{C}$ en algunos minutos-, y la espuma de arciIla, son excelentes aislantes, y poco costosos.

Los aislantes de síntesis son también interesantes, a condición de que sean ininflamables o, por lo menos, ignífugos.

Los materiales con células cerradas continúan oponiéndose a los de células abiertas, si bien es evidente que los primeros pueden tender a ser más eficaces, y a una impermeabilidad más efectiva frente al vapor de agua.

Antes de terminar esta exposición, forzosamente incompleta, ya que es constante la aparición de nuevos materiales o procedimientos, citaremos dos que tienen el interés de ser muy recientes.

El primero es un nuevo revestimiento que obtiene sus propiedades insonorizantes y de conservador térmico, de las fibras de celulosa, del amianto y de la vermiculita, que se entremezclan para formar un fieltro aislante. Se emplea en el interior para los muros y los cielorrasos, aplicándose sobre el hormigón, el cemento, la madera o el yeso, y dando un aspecto estampado de fuerte relieve. Se presenta, en forma de pasta espesa, en sacos de plástico, y se aplica a pistola con bote a presión con salida por la base, o bien, eventualmente, a la tirolesa para las pequeñas superficies.

El otro es un revestimiento fibroso para muros, que asegura un buen aislamiento acústico y térmico en los edificios de viviendas múltiples. Este revestimiento ofrece un poder guarnecedor elevado, permitiendo la supresión de las operaciones de revoco y de raspado. Como no es electrostático, no retiene el polvo, pudiéndose utilizar en el interior sobre los muros o sobre el cielorraso. Se presenta bajo forma de pasta espesa acondicionada en saco de plástico, y puede aplicarse con brocha cuadrada, rodillo, a la tirolesa, con espátula o también a pistola con bote de salida a presión baja.

Todos estos materiales son susceptibles de conseguir motivos decorativos simples y poco costosos.

¿Cuál puede ser la conclusión? Intentemos darla lo más objetivamente posible.

En la confrontación de diversos materiales, el más comercial es, frecuentemente, el que está basado en sólidos datos técnicos.

Lo que hace falta buscar es una disminución de las fluctuaciones de temperatura en un local, a nivel de albañilería, con lo que se conseguiría una mejor regulación de la calefacción y un aumento del confort, tanto en invierno como en verano.

Además, es bien conocido que el choque térmico agrava el riesgo de degradación de una pared. Con esto se vuelve a la discusión abierta entre aislamiento por el interior o por el exterior. Lo esencial será, para el arquitecto, saber qué aislar y cómo.

Los materiales de que puede disponer son de sobra conocidos, por lo tanto su propia experiencia le ayudará a elegir. 


\section{résumé}

Les bardages industriels, les revêtements de façades et les problèmes d'îsolation

Georges Rodríguez

Chaque jour, en construction, de nouvelles techniques apparaissent pour résoudre, d'une manière plus effective, les problèmes de toujours ou ceux qui peuvent se poser aux
ouvrages actuels.

Les revêtements de façade et de couverture sont un chapitre important à l'heure de protéger et d'accroîte la vie de l'immeuble. A cette fin, on peut utiliser les tôles nervurées prélaquées, les bardages en feuilles deuilles, bien le cuive et le plomb en leur prix élevé, sont réservés aux très beaux immeubles et aux monuments réputés "éternels". Pour les constructions courantes on utilise les plaques en amianteciment, d'une grande variété de formes et de qualités, servant également à l'isolation de murs. Le verre armé est de nouveau

II est difficile de résoudre les problèmes d'isolation des immeubles d'habitation si l'on n'utilise pas les matériaux et les systemes appropriés. La pose $d$ 'un bon isolant protége contre Thumidité et amène une chaleur. II existe une grande diversité de ces matériaux, de l'amiante aux argiles, passant par les isolants de synthèse, jusqu'aux matériaux les plus modernes obtenus grâce au mélange de fibre de celluose, amiante et vermiculite. En dernier recours, le projeteur doit décider s'if convient une isolation interieure ou extérieure plus positif.

\section{summary}

Industrial claddings, façade facings and insulation problems

Georges Rodríguez

In the construction line new techniques appear every day in order to find a more constantly arising problems or to those that may arise in current work.

The facing of outer walls and façades is an important chapter when in comes to protect. ing and prolonging the life-time of buildings. steels can be used, as well as these clad with aluminium, copper and lead sheets although the two latter ones are generally reserved for very few monumental buildings, due to their high price. In ordinary type buildings asbest-cement sheets are used, in different shapes and qualities and which also sene as insulation of its great rigidity.

The insulation problems in housing are difficult to solve unless appropriate matea good insulant protects from dampness ond saves heat. There is a great variety of these materials, on one hand asbestos, clay and synthetic materials and on the other most modern products, obtained by mixing cellulose fiber, asbestos and vermiculite. Finally, the designer should consider whether with interior question should be equipped to achieve the best result.

\section{zusammentassung}

Industrie- und Fassadenverkleidung und Insolierungsprobleme

Georges Rodríguez

Im Bauwesen tauchen taglich neue Verfahren auf, in der Absicht nicht nur die üblichen Probleme effektiver zu losen, sondern auch die, die in gegenwartigen Arbe

Wenn es darauf ankommt, das Leben eines Gebäudes zu schützen und zu verlängern, ist die Verkleidung von Dachern und Fassaden diesem Zweck folgende Materialien ner zu det werden: vorlackierte gerippe Stahlbleche Verkleidung aus Aluminium-, Kupfer- und Bleitafeln, wenn auch die beiden letzteren wegen des hohen Preises nur in wenigen, monumentalen Bauten gebraucht werden. In gewöhnlichen Gebauden wie in Mauern werden Asbestzementbleche verschiedener Glas wird Qualitaten benutzt. Armiertes auch wieder bevorzugt.

Die Isolierungsprobleme in Wohnhäusern können schwer zu lösen sein, wenn die eroraucht Isolierstoffes schutzt vor Feucht und spart Wärme. Es gibt hier eine grosse Auswahl, wie z.B. Asbest, Ton und Kunststoffe, unter denen die modernsten aus einer Mischung von Zellulose-, Asbest- und Vermikulitfasern bestehen. Als letzte Massnahme soll der Entwurfsarbeit noch erwägen ob das $\mathrm{Ge}$ baude mit innen- oder Aussenisolierung ver. zu erreichen.

\section{publicación del i.e.t.c.c. protección química de la construcción}

HANS KÖLZOW

Dr. Químico Dipl.

Stadtbaurat a.D.

La importancia creciente que se concede a la protección química de las obras de fábrica y la carencia de un tratado que reúna toda la literatura dispersa que existe sobre el tema, han llevado a la publicación de este libro, que debe leerse con atención en todas y cada una de sus páginas a fin de que nada resulte incomprensible.

En la Technische Akademie de Wuppertal el autor celebró, durante los últimos años, ocho seminarios, de tres días de duración cada uno, sobre protección de obras. Los participantes a estos seminarios han sido arquitectos e ingenieros procedentes de organismos oficiales y de empresas privadas, así como químicos de las industrias dedicadas a la fabricación de sistemas y métodos químicos protectores. De las conferencias y de los coloquios consiguientes se han obtenido resultados importantes y esperanzadores que merecen ser conocidos por círculos mucho más amplios. Por todo ello se ha creído conveniente la publicación del presente resumen, indicando expresamente que, de ningún modo, se trata de un manual ni de un libro de recetas.

Encuadernado en rústica, de $17 \times 24 \mathrm{~cm}$, compuesto de 74 páginas. Madrid, 1971 .

Precios: España: 300 pesetas. Extranjero: \$ 6. 